\title{
RANCANG BANGUN ALAT DETEKSI PENYIMPANGAN DEFORMASI BENDING DI PT. $X$
}

\author{
Muhammad Syafri Lubis ${ }^{1}$, Margono Sugeng ${ }^{2}$ \\ 1, 2 Program Studi Teknik Mesin, Institut Sains dan Teknologi Nasional, Jakarta Selatan \\ Email: syafriimuhammad@yahoo.com
}

\begin{abstract}
PT. $X$ is an automotive manufacturing that produce kind of any vehicle on Indonesia. Bending process is one of process system in PT. X. As the biggest manufacturing which have so many consument in Indonesia, on time delivery is an important things that have to kept costumer smile achievement. From the main factor before if any proces that related delay delivery have to fastly contermeasure and standardization guarantee for reoccurance problem. With using 6 step Kaizen methode and focus to bending frame assy process and frame assy robot process that give the biggest impact to delivery, so as this reason the author make a target for both process can be guaranted as process delivery.
\end{abstract}

Keywords: Deformation, Frame Assy, bending frame

\section{PENDAHULUAN}

Di Era globalisasi saat ini, automotive adalah sebuah industri yang sangat berkembang. Hal ini dapat terlihat, dengan berkembangnya industri automotive saat ini terutama di Indonesia. Automotive bukan lagi dianggap sebagai barang mewah, dalam berbagai aspek masyarakat saat ini automotive merupakan kebutuhan untuk dapat menjalankan roda kehidupan.

Untuk menjaga kondisi pasar diatas, selain dari pada kualitas maka on time delivery ke konsumen juga memegang peranan penting dalam proses produksi. PT. X sebagai affiliasi dari pabrikan mobil terbesar di dunia saat ini, sangat menjaga hal ini agar lancarnya kondisi bisnis saat ini. Untuk dalam menunjang hal tersebut maka meminimalisir line stop adalah peranan penting yang harus dijaga.

Beberapa waktu lalu, di PT. X sering terjadi masalah errornya mesin robot (Rearc-I) pada saat melakukan proses. Secara mesin robot tidak ada masalah, dan yang menjadi masalah adalah output dari mesin proses sebelumnya yaitu FTA-II proses. Ternyata mesin tersebut dalam kondisi yang tidak maksimal, namun hanya diketahui ketika output menjadi masalah di proses selanjutnya.

Namun, dalam menanggapi kasus ini terdapat dua permasalahan yang harus diselesaikan dalam hal ini adalah problem leakage dan problem detection yang menyebabkan problem ini menjadi outflow ke proses selanjutnya.

\section{TINJAUAN PUSTAKA}

Dalam Hal ini perlu diketahui dasar-dasar teori mengenai bagaimana pengukuran, pengendalian proses, sifat-sifat mekanik suatu bahan, tegangan dan regangan yang diterima oleh bahan.

\section{Teknik Pengukuran}

Pengukuran adalah penentuan nilai dari besaran, dimensi, ataupun suatu kapasitas dari nilai standard atau satuan ukur. Pengukuran tidak hanya terbatas pada suatu kuantitas fisik, tetapi juga dapat diperluas untuk mengukur hampir semua benda yang dapat dibayangkan, seperti angka ketidakpastian, atau level kepercayaan konsumen.

\section{Metrologi Pengukuran}

Metrologi mencakup kedalam tiga hal utama yaitu: Pertama, penetapan definisi satuansatuan ukuran yang diterima secara internasional, misalkan saja adalah meter, kilogram, dsb. Kedua, perwujudan satuansatuan ukuran berdasarkan metode-metode ilmiah, missal perwujudan nilai meter menggunakan gelombang cahaya laser. Ketiga, penetepan rantai ketertelusuran dengan menentukan dan merekam nilai dan akurasi suatu pengukuran dan menyebarluaskan pengetahuan tersebut, misalnya hubungan (perbandingan) antara nilai ukur sebuah 
mikrometer ulir terhadap balok ukur sebagai standar panjang di laboratorium.

Sensor

Sensor adalah sesuatu yang digunakan untuk mendeteksi adanya perubahan lingkungan fisik atau kimia. Variabel keluaran dari sensor yang diubah menjadi besaran listrik disebut Transduser. Pada saat ini, sensor tersebut telah dibuat dengan ukuran sangat kecil dengan orde nanometer. Ukuran yang sangat kecil ini sangat memudahkan pemakaian dan menghemat energi.

\section{Enam Langkah Kaizen}

Secara umum, ada enam langkah utama dalam Kaizen, Gambar 2.9, dan langkahlangkah itu serupa dengan metodologi lain, seperti metode ilmiah dan pemecahan masalah. Sebagaimana yang akan didiskusikan sepanjang sisa buku kerja ini, perbedaan yang mendasar adalah dalam kaizen terdapat tingkat kebebasan yang lebih tinggi dan penekanan yang lebih besar pada pencetusan ide orisinal. Secara umum, semua metodologi perbaikan mengikuti suatu pola dasar, yaitu Rencanakan-LakukanPeriksa-Perbaiki, dan proses kaizen tidaklah berbeda.

\section{Seven Tools}

Dalam seven tools dinyatakan bahwa dalam melakukan suatu penelitian dibutuhkan 7 alat bantu sebagai penunjang pengorganisasian masalah. Pertama, check sheet. Kedua, stratifikasi. Ketiga, diagram pareto. Keempat, diagram sebab akibat. Kelima, control chart. Keenam, histogram. Ketujuh, scatter diagram.

\section{Pengendalian Proses}

Kualitas suatu produk merupakan salah satu faktor penting dimana menjadi kunci suatu perusahaan dalam menjaga daya saingnya untuk lebih berkembang dibandingkan dengan kompetitornya. Dalam menghasilkan output produksi yang bagus, maka disetiap proses pembuatan suatu produk jadi haruslah dikontrol secara kontiniu. Pengontrolan terhadap kualitas suatu produk dapat dilakukan dengan cara statistic dengan menggunakan metode SPC (Statistical Process Control).

\section{Sifat Mekanik Bahan}

Sifat mekanik didefinisikan sebagai ukuran kemampuan bahan untuk membawa atau menahan gaya atau tegangan. Pada saat menahan beban, atom-atom atau struktur molekul berada dalam kesetimbangan. Gaya ikatan pada struktur menahan setiap usaha untuk mengganggu kesetimbangan ini, misalnya gaya luar atau beban.

\section{Tegangan}

Tegangan adalah tahanan material terhadap gaya atau beban. Tegangan diukur dalam bentuk gaya per luas. Tegangan normal adalah tegangan yang tegak lurus terhadap permukaan dimana tegangan tersebut diterapkan. Tegangan normal berupa tarikan atau tekanan. Satuan SI untuk tegangan normal adalah Newton per meter kuadrat $\left(\mathrm{N} / \mathrm{m}^{2}\right)$ atau Pascal $(\mathrm{Pa})$.

$$
\sigma=\frac{F}{A}
$$

Keterangan:

$\sigma=$ Tegangan $\left(\mathrm{N} / \mathrm{mm}^{2}\right)$

$\mathrm{F}=$ Gaya $(\mathrm{N})$

$\mathrm{A}=$ Luas $\left(\mathrm{mm}^{2}\right)$

\section{Regangan}

Regangan didefinisikan sebagai

perubahan ukuran atau bentuk material dari

panjang awal sebagai hasil karya dari gaya yang menarik atau yang menekan pada material.

Apabila suatu spesimen struktur material diikat pada jepitan mesin penguji dan beban serta pertambahan panjang spesifikasi diamati serempak, maka dapat digambarkan pengamatan pada grafik dimana ordinat menyatakan beban dan absis menyatakan pertambahan panjang.

$\varepsilon \quad=$ Regangan $(\%)$

$$
\varepsilon=\frac{\Delta l}{l o}
$$

$\Delta l=$ Perubahan Panjang $(\mathrm{m})$

lo $=$ Panjang awal $(\mathrm{m})$

\section{METODE DAN PENGOLAHAN DATA}

Dalam hal pemecahan masalah, metode yang digunakan adalah dengan menggunakan metode 6 langkah kaizen. Dengan proses pengumpulan data di PT. X dalam hal ini, metode pengumpulan data dilakukan secara langsung. Berawal dari latar belakang masalah dan tujuan masalah, lalu dilanjutkan untuk melakukan kalrifikasi masalah dengan data-data yang tersedia dilapangan. Dari permasalahan yang ditemukan, maka dilakukan breakdown analysis sehingga dapat diketahui apa yang sebenarnya menjadi pokok dari permasalahan. Setelah mendapatkan pokok permasalahan maka selanjutnya untuk mulai melakukan perencanaan perbaikan. 


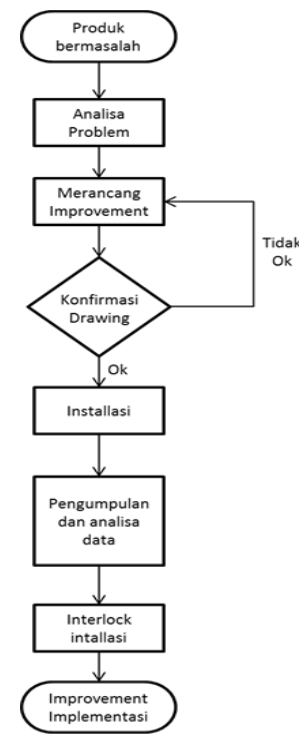

Gambar 1. Flow chart metode penelitian

\section{Prosedur Pengambilan Data}

Untuk penunjang dalam pengumpulan data, dalam hal ini maka perlu diketahaui bagaimana kondisi produktifitas yang terjadi dalam kurun waktu 3 bulan terakhir. Sementara itu, dalam satu bulan (Maret 2016) terakhir di PT. X, terjadi permasalahan $J I G$ error di robot Frame Assy proses yang menghambat kelancaran produksinya. Dalam hal ini, permasalahan ini terjadi sebanyak 5.18 kali perharinya dari rata-rata kejadian dalam bulan maret 2016.

\section{Alat Yang Digunakan}

Untuk menentukan alat apa saja yang akan digunakan dalam hal ini adalah pertama sekali penulis mencoba untuk melihat kondisi area yang akan menjadi objek deteksi deformasi bending. Perlu beberapa hal yang menjadi pertimbangan lanjutan dalam menentukan improvement ini. Pertama, pertimbangan terhadap space yang tersedia haruslah bisa memberikan referensi untuk alat apa yang akan digunakan sebagai perbaikan. Kedua, pertimbangan terhadap kondisi lingkungan juga menjadi perhatian dalam pemilihan perbaikan. Ketiga, bagaimana kecenderungan mesin yang akan diperbaiki.

\section{Spesifikasi Data}

Dalam hal ini, pressure yang diberikan oleh mesin bending sangat menentukan hasil bentuk dari benda kerjanya. Secara standard pressure yang diberikan oleh mesin terhadap benda kerja adalah min. $290 \mathrm{kN}$. Namun, seperti yang sudah disebutkan sebelumnya pada latar belakang masalah bahwa yang pressure actual adalah $140-180 \mathrm{kN}$.

Tabel 1. Tabel pressure actual mesin bending

\begin{tabular}{|c|c|c|c|}
\hline Cylinder 1 & Cylinder 2 & Cylinder 3 & Cylinder 4 \\
\hline $140 \mathrm{KN}$ & $160 \mathrm{KN}$ & $180 \mathrm{KN}$ & $180 \mathrm{KN}$ \\
\hline
\end{tabular}

\section{Perhitungan Getaran Center Register}

Benda kerja atau yang lebih sering juga dikenal dengan sebutan part merupakan produk yang akan dibentuk di setiap proses. Butuh keakuratan dari benda kerja yang sesuai dengan kondisi mesin untuk mendapatkan smooth proses. Berdasarkan hal tersebut pula, yang menuntun penulis untuk menganalisa bagaimana kondisi benda kerjanya.

Langkah pertama penulis mencoba untuk membandingkan bagaimana sebenarnya kondisi benda kerja yang menyebabkan masalah dengan kondisi benda kerja yang tidak menyebabkan masalah. Dari kegiatan ini ditargetkan untuk dapat mengetahui kondisi benda kerja yang ideal untuk dapat diproses oleh mesin. Gambar dibawah adalah merupakan grafik yang menggambarkan perbedaan benda kerja (frame assy) dalam kondisi ideal dengan benda kerja (frame assy) dalam kondisi problem.

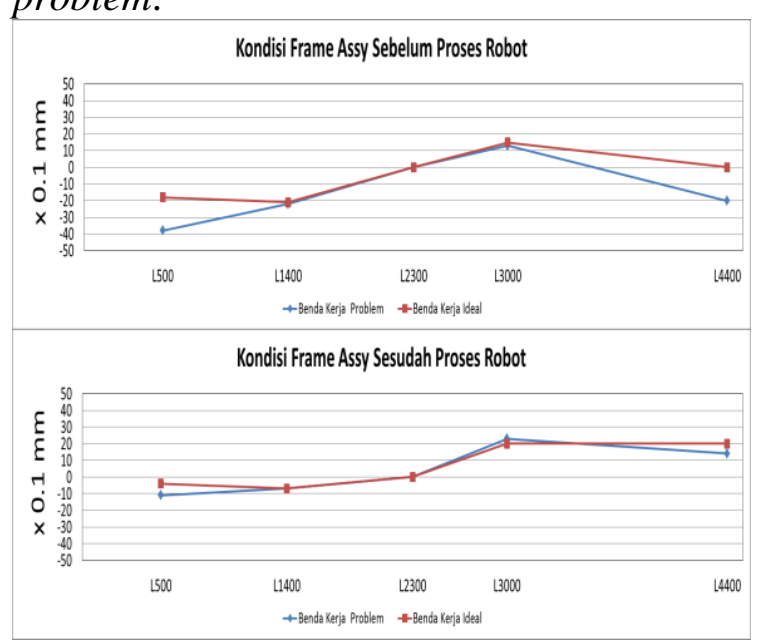

\section{Pengolahan Data}

Dari data yang didapatkan bahwa terdapat perbedaan deformasi yang terjadi pada output mesin bending. Yang dalam hal ini, juga diikuti dengan kurangnya pressure dari mesin bending itu sendiri. Maka, dengan menghitung perbedaan regangan yang terjadi antara kedua kondisi yang berbeda tersebut adalah bisa terlihat dengan menghitung beban atau force yang diberikan pada benda kerja. 
Dengan menjabarkan persamaan di atas, maka akan didapatkan suatu persamaan pendekatan sebagai berikut :

$\Delta l=F$ (Persamaan IV)

Dapat disimpulkan dari persamaan di atas adalah bahwa $\Delta I$ akan sebanding linier terhadap $F$ yang diberikan. Sehingga untuk menghubungkan hal tersebut dapat dihubungkan dengan rumus sebagai berikut:

$$
\frac{F 1}{F 2}=\frac{\Delta l 1}{\Delta l 2} \ldots \ldots \ldots . .(\text { Persamaan } \mathrm{V})
$$

Maka dari nilai pressure yang diberikan mesin bending terhadap benda kerja pada kondisi terjadi masalah adalah sebesar $165 \mathrm{kN}$ (F2). Dan dengan kondisi normal pressure sebesar $290 \mathrm{kN}$, perubahan deformasi ( $\Delta l 1)$ yang diberikan terhadap benda kerja adalah sebesar $3.0 \mathrm{~mm}$. Maka, dapat diketahui bahwa nilai perubahan deformasi pada saat kondisi bermasalah $(\Delta l 2)$ adalah;

$$
\Delta l 2=\frac{3.0 \mathrm{~mm} * 165 \mathrm{kN}}{290 \mathrm{kN}}=1.7 \mathrm{~mm}
$$

Dengan mengetahui nilai dari $\Delta l 2$ dan untuk mengetahui berapa besar regangan yang dialami pada kondisi tersebut adalah:

$$
\varepsilon=\frac{1.7 \mathrm{~mm}}{50 \mathrm{~mm}}=3.4 \%
$$

Jika nilai regangan yang diakibatkan oleh pressure $F 2$ adalah $3.4 \%$, agar nilai $\Delta l 2 \approx$ $\Delta l 1$ maka dengan kondisi $\Delta l 2$ diberikan pressure F2 kembali, akan didapatkan nilai $\Delta l 3$ sebagai stabilisasi nilai $\Delta l 2$ yang kondisinya dibawah dari nilai yang diinginkan.

$$
\varepsilon=\frac{\Delta l}{l o} \ldots \ldots \ldots \ldots . . .(\text { Persamaan } \mathrm{I})
$$

$3.4 \%=\frac{\Delta l 2^{\prime}}{(50+1.7) \mathrm{mm}}$

$\Delta l 2^{\prime}=3.4 \% * 51.7 \mathrm{~mm}$

$\Delta l 2^{\prime}=1.75 \mathrm{~mm}$

Sehingga nilai dari $\Delta l 3$ adalah sebagai berikut : $\Delta l 3=\Delta l 2+\Delta l 2^{\prime}$

$$
\Delta l 3=1.7+1.75=3.45 \mathrm{~mm}
$$

Dari perhitungan di atas dapat disimpulkan bahwa dengan kondisi pressure F2, jika benda kerja dilakukan proses rebending maka nilai deformasi yang akan diterima oleh benda kerja tersebut akan equivalen terhadap nilai deformasi normalnya.

\section{ANALISIS HASIL}

\section{Perancangan Alat}

Dalam perancangan alat yang akan dibuat adalah bagaimana membuat suatu alat yang dapat menjadi pendeteksi output dari benda kerja, bahwa tidak akan ada benda kerja yang tidak sesuai dengan kondisi ideal yang masuk ke proses pengelasan robot. Untuk itu, memahami bagaimana kondisi suatu proses harus menjadi point penting dalam hal ini.

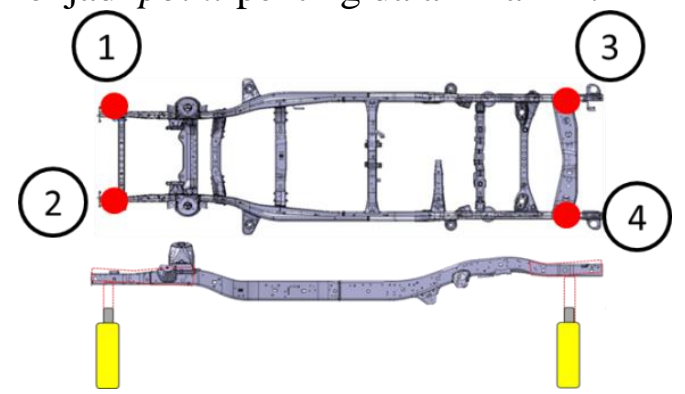

Gambar 4.1 Ilustrasi proses bending

Dari gambar diatas terlihat bahwa proses bending terjadi benda kerja dimana ada 4 titik yang menjadi poin proses bending. Pada masing-masing poin ini akan menjadi objek yang akan di deteksi oleh sensor yang digunakan.

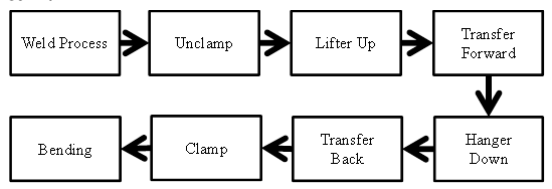

Gambar 4.2 Urutan step kerja pada mesin bending proses

Pada gambar 4.2 dapat terlihat bahwa setelah bending proses sudah tidak ada proses selanjutnya yang dapat menjadi garansi output setelah bending sudah dalam kondisi ideal atau tidak. Untuk secara step kerja mesin juga perlu untuk dilakukan pengubahan sebagai bahan awal untuk melakukan improvisasi mesin.

Sebagai bahan pertimbangan dalam menjaga output dari hasil bending maka secara secara step kerja dari mesin akan ditambahkan proses pengukuran dari output benda kerja mesin sendiri. Sehingga nantinya setelah dilakukan bending proses maka akan dilakukan pengukuran terhadap benda kerja tersebut. Karena alat yang akan dibuat adalah untuk menggaransi hasil dari bending proses, maka apabila hasil dari bending tidak sesuai dengan yang diinginkan akan dilakukan proses bending kembali. Pada gambar 4.3 adalah bagaimana step kerja dari mesin bending proses, yang 
diubah agar dapat menggaransi kondisi benda kerja yang ideal.

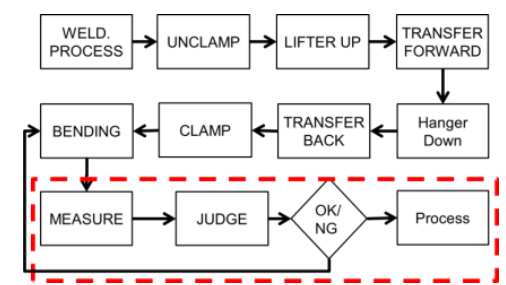

Gambar 4.3 Urutan step kerja pada mesin bending proses yang diimprovisasi.

Sensor yang akan digunakan dalam hal ini sangat perlu dipertimbangkan mengingat faktor lingkungan akan sangat mempengaruhi kinerja dari sebuah sensor. Pada gambar sebelumnya yang telah disebutkan di bab III, bahwa range temperatur pada proses mesin bending adalah berada pada $25^{\circ} \mathrm{C}-36^{\circ} \mathrm{C}$. Untuk itu, hal ini menjadi salah satu acuan dalam pemilihan sensor.

Seperti yang sudah dijelaskan sebelumnya terkait dengan percancangan alat, bahwa nantinya penulis akan menggunakan 4 buah sensor sebagai pendeteksi hal benda kerja. Sensor-sensor ini akan ditempatkan dekat dengan benda kerja yang mengalami secara langsung proses bending ini. Untuk itu posisi ini akan digambarkan kedalam sketsa konsep pada gambar 4.5.

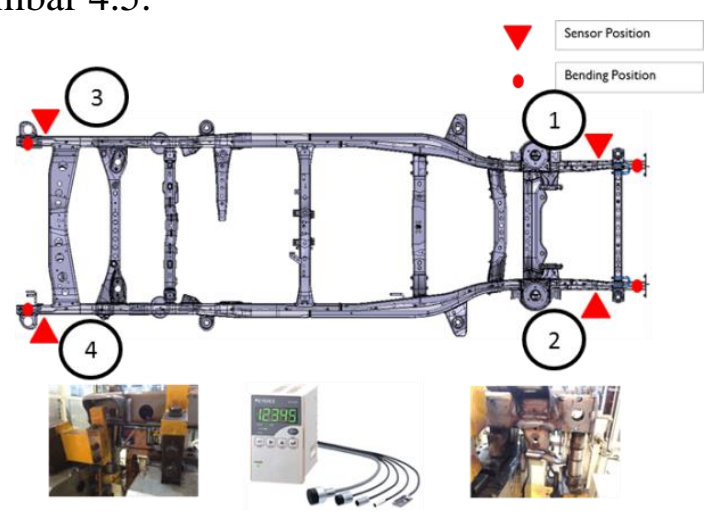

Gambar 4.5 Sketsa konsep pemasangan sensor

Dengan dimensi sensor yang hanya berukuran $47.0 \times 52.5 \times 24.1 \mathrm{~mm}$ (dapat terlihat pada gambar 4.6). Dengan space yang tersedia seluas 40x150x500 mm. Maka, dibutuhkan supporting sebagai penyangga sensor agar bisa terposisi secara independent untuk mendetek benda kerja. Selain berfungsi sebagai penyangga, sensor juga harus diberikan cover sebagai pelindung untuk menjaga sensor dari debu ataupun dust manufacturing .

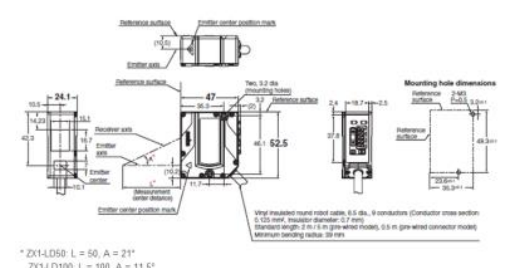

Gambar 4.6 Dimensi sensor (Omron Catalogue, 2016)

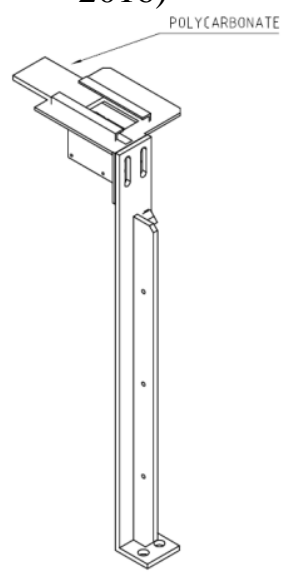

Gambar 4.7 Support sensor measurement

Gambar 4.8, adalah Sensor yang digunakan berfungsi sebagai alat ukur benda kerja. Sensor ini akan mengukur posisi dari benda ukur tersebut sehingga posisi inilah yang menjadi tolak ukur sebagai kondisi yang diinginkan. Tentunya penyesuaian jarak antara sensor dengan benda kerja haruslah tidak menimbulkan efek terhadap keakuratan deteksi sensor.

\section{Instalasi Interlock Rebending}

Pada tahap awal endurance trial sensor digunakan untuk melakukan recording data sebanyak 2199 data. Dari data tersebut akan diambil sampling sebanyak 100 data dan diolah untuk mendapatkan nilai toleransi terbaiknya agar nantinya bisa dijadikan datum judgement terhadap $\mathrm{OK}$ atau tidaknya hasil bending terhadap benda kerja, sebagaimana ditunjukkan pada tabel 4.1.

Tabel 4.1 Sampling data endurance trial

\begin{tabular}{|c|c|c|c|c|c|c|c|c|c|c|}
\hline & \multicolumn{2}{|c|}{ x $0.1 \mathrm{~mm}$} & \\
\hline & 1 & 2 & 3 & 4 & 5 & 6 & 7 & 8 & 9 & 10 \\
\hline 1 & 540 & 562 & 536 & 537 & 542 & 536 & 536 & 534 & 535 & 537 \\
\hline 2 & 534 & 535 & 539 & 539 & 538 & 545 & 544 & 543 & 552 & 554 \\
\hline 3 & 541 & 544 & 528 & 537 & 528 & 537 & 534 & 532 & 545 & 542 \\
\hline 4 & 541 & 537 & 537 & 545 & 546 & 545 & 541 & 543 & 540 & 542 \\
\hline 5 & 537 & 552 & 542 & 537 & 543 & 541 & 542 & 536 & 543 & 537 \\
\hline 6 & 554 & 538 & 537 & 540 & 531 & 534 & 543 & 547 & 549 & 541 \\
\hline 7 & 540 & 531 & 540 & 551 & 537 & 545 & 539 & 545 & 537 & 527 \\
\hline 8 & 541 & 537 & 539 & 541 & 547 & 537 & 536 & 537 & 535 & 536 \\
\hline 9 & 534 & 538 & 536 & 536 & 545 & 538 & 536 & 532 & 539 & 535 \\
\hline 10 & 527 & 544 & 529 & 537 & 534 & 543 & 536 & 541 & 534 & 534 \\
\hline
\end{tabular}

a) Menghitung Nilai Range 
Range $(\mathrm{R})=$ Nilai maksimum - Nilai minimum

$$
\begin{aligned}
& =562-527 \\
& =35
\end{aligned}
$$

b) Menentukan Jumlah Kelas

$$
\begin{aligned}
\text { Jumlah kelas }(\mathrm{k}) & =\sqrt{k} \\
& =\sqrt{100}=10
\end{aligned}
$$

c) Menghitung Interval atau Panjang Kelas

$$
\begin{aligned}
\operatorname{Interval}(\mathrm{h}) & =\frac{R \text { (Range) }}{k(\text { Jumlah Kelas })} \\
& =\frac{35}{100} \\
& =3.5(\text { Dibulatkan menjadi 4.0) }
\end{aligned}
$$

d) Menentukan Nilai Batas Kelas Atas dan Batas Kelas Bawah

Batas kelas bawah

$$
\begin{aligned}
& =\text { Nilai minimum }-\frac{\text { Ketelitian alat whwr }}{2} \\
& =527-\frac{3}{2} \\
& =525.5
\end{aligned}
$$

Batas kelas atas

$=$ Batas kelas bawah + Interval $(\mathrm{h})$

$=525.5+4.0$

$=529.5$

Untuk kelas kedua sampai yang terakhir, nilai

\begin{tabular}{|c|c|c|c|c|c|c|c|c|}
\hline \multirow{2}{*}{$\begin{array}{l}\text { No. Lot } \\
1 \\
\end{array}$} & \multicolumn{3}{|c|}{ Batas Kelas } & \multirow{2}{*}{$\begin{array}{c}\text { Nilai Tengah } \\
527.5\end{array}$} & \multirow{2}{*}{$\begin{array}{l}\mathrm{f} \\
5 \\
\end{array}$} & \multirow{2}{*}{$\frac{\mu}{-2}$} & \multirow{2}{*}{$\begin{array}{l}\mu . f \\
-10 \\
\end{array}$} & \multirow{2}{*}{$\frac{\mu^{2} . f}{20}$} \\
\hline & 525.5 & - & 529.5 & & & & & \\
\hline 2 & 529.5 & - & 533.5 & 531.5 & 4 & -1 & -4 & 4 \\
\hline 3 & 533.5 & - & 537.5 & 535.5 & 37 & 0 & 0 & 0 \\
\hline 4 & 537.5 & - & 541.5 & 539.5 & 23 & 1 & 23 & 23 \\
\hline 5 & 541.5 & - & 545.5 & 543.5 & 21 & 2 & 42 & 84 \\
\hline 6 & 545.5 & - & 549.5 & 547.5 & 4 & 3 & 12 & 36 \\
\hline 7 & 549.5 & - & 553.5 & 551.5 & 3 & 4 & 12 & 48 \\
\hline 8 & 553.5 & - & 557.5 & 555.5 & 2 & 5 & 10 & 50 \\
\hline 9 & 557.5 & - & 561.5 & 559.5 & 0 & 6 & 0 & 0 \\
\hline 10 & 561.5 & - & 565.5 & 563.5 & 1 & 7 & 7 & 49 \\
\hline & & & & Total & 100 & & 92 & 314 \\
\hline
\end{tabular}
batas kelas bawah dan batas kelas atas sama dengan nilai batas kelas bawah dan batas kelas atas nilai sebelumnya ditambahkan dengan interval kelas.

e) Tabel Distribusi Frekwensi

Berdasarkan dari perumusan yang sebelumnya sudah kita dapatkan maka dapat dituangkan dalam bentuk table distribusi frekwunsi sebagai berikut.

Tabel 4.2. Distribusi frekwensi sampling data

f). Menentukan Nilai Rata-Rata

Untuk mengetahui bagaimana kondisi ratarata unit yang diproduksi berdasarkan alat ukur ini adalah :

$$
\begin{aligned}
\operatorname{Rata}-\operatorname{rata}( & \bar{X})=535.5+h\left(\frac{\sum \mu f}{n}\right) \\
& =535.5+4.0\left(\frac{92}{100}\right) \\
& =539.18 \mathrm{~mm}
\end{aligned}
$$

Dari data tersebut didapatkan bahwa ratarata kondisi benda kerja hasil produksi didapatkan bahwa rata-rata data berdasarkan sensor ukur yang sudah dibuat adalah sebesar $539.18 \mathrm{~mm}$. Berdasarkan pembahasan sebelumnya bahwa terdapat perbedaan antara benda kerja ok dan tidak ok sebesar 20 x 0.1 $\mathrm{mm}$.

Maka untuk menentukan nilai minimum dari benda kerja sebagai trigger error mesin adalah sebagai berikut :

\section{Nilai minimum $=$ \\ (Nilai rata-rata) $-($ diff. benda kerja)}

Sehingga didapatkan nilai terendah yang akan di-judgement tidak ok oleh sensor ini adalah :

$$
\begin{aligned}
& \text { Nilai minimum }=539.18-20 \\
& \quad=519.2
\end{aligned}
$$

\section{(dibulatkan menjadi 520.0)}

Jadi berdasarkan kalkulasi yang diperoleh, sensor ini akan bekerja untuk memerintahkan proses bending ulang jika nilai dari benda kerja tersebut adalah kurang dari $520.0 \times 0.1 \mathrm{~mm}$. Dengan dijadikannya nilai tersebut sebagai trigger untuk melakukan proses re-bending, maka tidak akan adalagi masalah linestop di proses robot frame assy yang disebabkan oleh faktor kekurangan bending.

\section{Daily Management Control}

Melakukan pengontrolan terhadap kualitas benda kerja akan berjalan baik dengan semakin banyaknya besaran ataupun nilai yang dapat kita buat. Semakin banyaknya nilai maka 4 semakin banyak yang dapat dikontrol. Penerapan statistical process control dapat diterapkan untuk mengendalikan banyaknya nilai yang dimiliki.

Dalam alat yang dibuat kali ini seluruh data akan disimpan dalam sebuah file, dimana di setiap unit yang melalui proses ini akan terukur dan datanya tersimpan dalam memory recording. Dan data ini akan terkonversi dalam graphic tendency yang dapat dilihat dari display yang ada. Seperti yang terlihat dalam gambar 
4.9 bahwa graphic tendency dapat terlihat dari display tersebut.

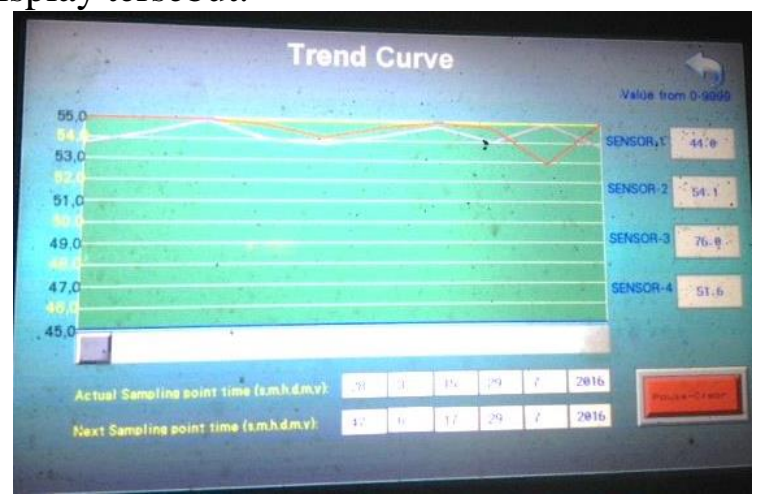

Gambar 4.9 Display graphic tendency output bending process

\section{Komparasi Hasil Improvement}

Berdasarkan data efficiency productivity yang diperoleh sejak dimulainya implementasi improvement ini, terlihat bahwa efficiency productivity ini mengalami kenaikan rata-rata sebesar $0.5 \%$. Seperti terlihat pada gambar 4.9, bagaimana kenaikan productivity di PT. X.

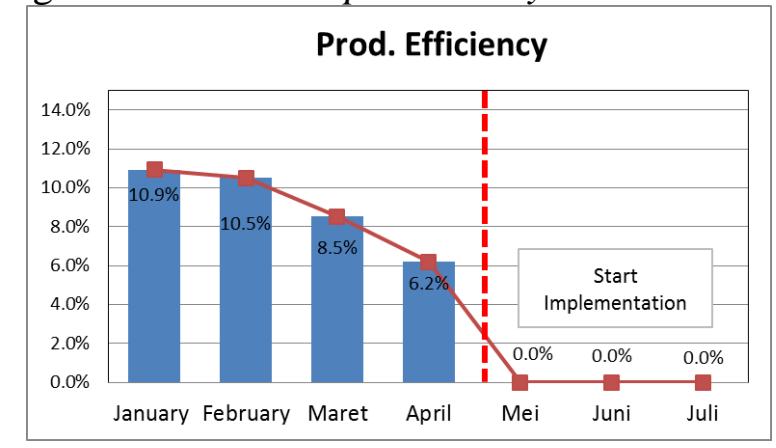

Gambar 4.10 Tendency masalah setelah implementasi

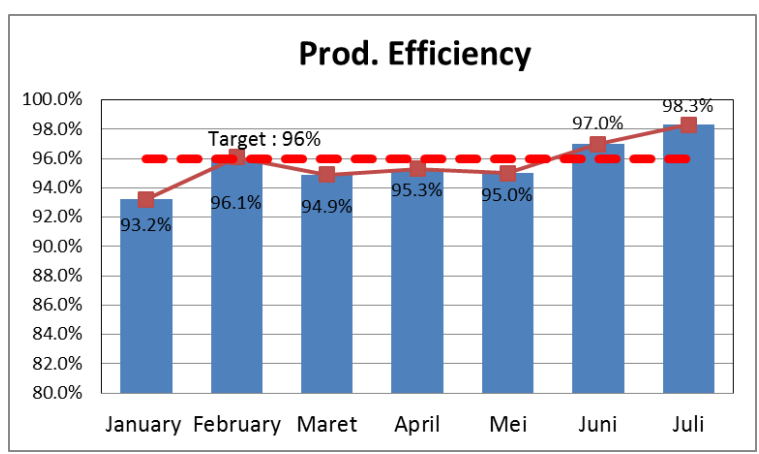

Gambar 4.11 Data effisiensi produksi setelah implemetasi improvement
Dari hasil penelitian yang dilakukan maka kesimpulan yang didapatkan adalah bahwa:

1. Bahwa dengan ditambahkannya alat pendeteksi deformasi hasil bending proses di PT. X, maka masalah clamp yang tidak sempurna pada proses rearc 1 dapat tertanggulangi.

2. Dengan mengkorelasikan kondisi sebelum dan sesudah improvement ini diimplementasikan, terlihat bahwa masalah yang diakibatkan dari bending proses dapat meningkatkan efficiency productivity sebesar $0.5 \%$.

3. Bahwa melalui hasil perhitungan yang didapatkan, kegagalan bending yang terjadi adalah rata-rata sebesar $1.7 \mathrm{~mm}$ dari besarnya regangan yang dialami oleh benda kerja pada kondisi normal.

4. Nilai deformasi bending yang terjadi pada benda kerja pada kondisi pressure senilai $165 \mathrm{kN}$ adalah senilai $1.7 \mathrm{~mm}$, dan dengan ditambahkannya program rebending maka hal ini dapat mengatasi kondisi gagal bending yang terjadi benda kerja jika pressure bending mesin tidak tercapai dimana nilai deformasinya akan equivalen terhadap pressure normalnya.

\section{DAFTAR PUSTAKA}

Alwasilah, Chaedar. 2008. Pokoknya

Kualitatif. Jakarta: Pustaka Jaya Anoraga, Panji. 2009. Manajemen Bisnis. Jakarta: Rhineka Cipta

Arikunto, Suharsini. 2010. Prosedur Penelitian Suatu Pendekatan Praktik. Yogyakarta: Rhineka Cipta.

Abahe. Quality Management Systems. 01 Desember 2007, 10.55 (Dikutip 25

Maret 2016). Tersedia dari : http://www.abahe.co.uk./businessadministration/Quality-ManagementSystems/

Businessballs. Quality Management System. 12 April 2000, 10.31 (Dikutip 25 Maret 2016). Tersedia dari: http://www.businessballs.com/dtiresourc es/quality management_system/

Danang Junaedi. Proposal Tugas Akhir. 28 Desembaer 2009, 11.24 (Dikutip 17 April 2016). Tersedia dari:

\section{KESIMPULAN}


http://danangjunaedi.files.wordpress.com/2009/ 10/format-proposal-tugas-akhir.pdf

Isao Kato dan Art Smalley (2014). Toyota Kaizen Methods 6 Langkah Perbaikan. Gradien Mediatama. Yogyakarta.

Montgomery, Douglas C. 2009. Introduction to Statistical Quality Control.United States: John Wiley \& Sons.

Yoriwe, Taufik. Teknik Mesin : Sifat Mekanik Bahan. February 2013, 09.51 (Dikutip 4 Maret 2017). Tersedia dari:

http://taufik-yoriwe.blogspot.com/2013/02/sifat$\underline{\text { mekanik-bahan.html }}$ 